\title{
Corruption and Levels of Economic Development: A Cross-Country Assessment with Special Reference to Africa
}

\author{
Raul Gouvea, Shihong Li, Gautam Vora \\ Anderson School of Management, University of New Mexico, Albuquerque, USA \\ Email: rauldg@unm.edu, shli@unm.edu,vora@unm.edu
}

How to cite this paper: Gouvea, R., Li, S. and Vora, G. (2019) Corruption and Levels of Economic Development: A Cross-Country Assessment with Special Reference to Africa. Modern Economy, 10, 2063-2084. https://doi.org/10.4236/me.2019.109130

Received: April 27, 2019

Accepted: September 20, 2019

Published: September 23, 2019

Copyright $\odot 2019$ by author(s) and Scientific Research Publishing Inc. This work is licensed under the Creative Commons Attribution International License (CC BY 4.0).

http://creativecommons.org/licenses/by/4.0/

\section{cc (i) Open Access}

\begin{abstract}
Cross-country studies of corruption have reported a negative relationship between corruption and economic development. Yet the causal direction is unclear. We posit that the relationship between corruption and economic development is innately interdependent or bidirectional because they coevolve within a country. Moreover, corruption and economic development interact with governance, culture, and social development, forming an interdependent system of quintuple helix. We examine these factors with a sample of 157 countries, as well as a subsample of 46 African countries. The results indicate that as countries move away from a factor-driven economy towards an innovation-driven economy, they observe lower levels of perceived corruption. However, the relationship between actual incidence of corruption and economic development is highly sensitive to covariates in governance, culture, and social development, consistent with interdependence among these factors. The factor that consistently explains perceived and actual corruption is a country's governance systems, measured by institutions or press freedom.
\end{abstract}

\section{Keywords}

Corruption, Economic Development Stage, Africa, African Countries, Institutions, Press Freedom, Regression Analysis

\section{Introduction}

Whereas corruption practices exist all over the world, the degree thereof differs for different countries. Some countries show lower levels of corruption than others; none, however, shows absence. One inescapable conclusion is that corruption is related to a country's level of economic development. However, the 
direction of the causality is still being debated [1]. This paper assesses to what extent corruption is related to a country's stage of economic development, and how this relationship is sensitive to a country's governance systems, culture, and social development. We argue that corruption coevolves with a country's political processes (or effectiveness of governance), culture, social norms, and similar factors. Thus, it becomes imperative to approach corruption from a multidimensional perspective.

There are different forms of corruption affecting different parts of the society, such as public sector, political sector, and private sector; they can be domestic or international [2]. The common feature is that corruption tends to impose and constitute a "tax" on the society, where gains are privatized by the local and global corruption networks and losses from corruption schemes are shared in different degrees by the rest of the society. Corruption deeply affects a country's quest to achieve an inclusive, equitable, and sustainable economy as well as political and social development [3] [4] [5] [6] [7].

Effective governance is an integral component of a country's quest to implement transparency at all levels in its social, economic, and political dimensions. A balanced and effective governance approach will eventually lead to and foster a country's structural transformation. On the other hand, poor levels of effective governance can lead to a number of economic, social, and political disruptions including corruption. Corruption is motivated by individual and institutional choices in a society. These choices, while shaping the expansion of corruption networks, are themselves shaped by the country's political, economic, social, and cultural environment. Thus, the corruption phenomenon needs to be understood from a broader perspective [8].

We posit that the relationship between corruption and economic development is innately interdependent or bidirectional because they coevolve within a country. Moreover, corruption and economic development interact with governance, culture, and social development, forming an interdependent system of quintuple helix. We examine these factors with a sample of 157 countries, as well as a subsample of 46 African countries. The results indicate that as countries move away from a factor-driven economy towards an innovation-driven economy, they show lower levels of perceived corruption. However, the relationship between actual incidence of corruption and economic development is highly sensitive to covariates in governance, culture, and social development, consistent with interdependence among these factors. This pattern is more pronounced among African countries. The factor that consistently explains perceived and actual corruption is a country's governance systems, measured by institutions or press freedom.

Our findings have policy implications for the worldwide battle against corruption and especially the anti-corruption efforts of African countries. Corruption is not a fixed feature of underdeveloped economies; but to combat poverty and corruption, a country must address its governance issues by establishing institutions of law and order and promoting transparency in executive, legislative, and 
judiciary decisions. It is of paramount importance for African countries to invite the participation of their civil societies in their political, social, and economic transformations.

The remainder of the paper is organized as follows. Section 2 discusses the special challenges faced by African countries in economic and social development. Section 3 develops the theoretical framework and describes the empirical methodology. Section 4 reports the empirical results. Section 5 concludes with discussion of limitations and policy implications.

\section{Corruption: An African Perspective}

Since the African colonies started gaining independence, Africa has attracted much attention for its endemic corruption. Despite its rich endowment in natural and human resources, Africa remains one of the poorest, undeveloped/underdeveloped regions in the world. African countries have experienced dramatic transformation of economy and society in the past decades. For instance, the increasing urbanization, a substantial change in fertility rates, and increasing ties to globalization forces are reshaping these countries' economies and societies [9] [10]. Nonetheless, many African countries are still lacking in basic education, health care, infrastructure, and human security. Most of the African nations show very low levels of economic complexity and competitiveness. All international agencies regard corruption as one of the main problems facing these countries. Many argue that these countries need strong institutions, a stable macro and micro economic environments, and a more conducive environment for the private sector to be the main economic driver. [4] [10] [11] [12].

Corruption in Africa takes many forms, from "petty corruption", bureaucratic, economic, and "grand corruption." Many cases of "grand corruption" have ties to international networks of corruption. Some foreign companies engage in corruption schemes to protect their interests in African countries. In addition to unlawful financial transactions, trafficking of humans and animals, illegal drugs and arms are also sources of funds for corruption schemes in the region [2] [6] [13]. Corruption incontrovertibly violates the human rights of millions of Africans by devouring resources that would otherwise be used to provide social services. Experts agree that the "bottom of the pyramid" in Africa is bearing the brunt of corruption [14] [15] [16]. "If you attack corruption, it's the best way to attack poverty," according to Nuhu Ribadu, the former head of Nigeria's anti-corruption commission. Therefore, a better understanding of the intricate working of corruption and its related factors in the African context has important implications.

Africa's colonial past certainly left deep scars on the continent. Colonial practices left a legacy of favoritism, despotic rulers, unchecked power structures, absolute rule above scrutiny, and economic rent-seeking activities. The "divide and rule" strategy implemented by many European colonial powers further extended the reach of corruption networks in several countries in Africa [17] [18] 
[19] [20]. After independence, favored groups under the colonial system seized power and perpetuated the cycle of abusive practices. These groups privatized the country's wealth or gains and socialized their economic losses, resulting in centralization of political and economic power [5] [7] [21].

These self-reinforcing and self-perpetuating political and economic systems have captured power in several countries, deeply affecting African countries' attempts to engage in governance favorable to sustainable politico-socio-economic development. The lack of "checks and balances" across the executive, judiciary, and legislative branches of government has resulted in endemic corruption throughout the continent. The corruption, in turn, has prevented these countries from establishing and adopting deep institutional reforms that could mitigate some forms of corruption. Despite recent attempts to privatize and engage in market-oriented reforms, the lack of transparency and accountability by the local African elites have hindered both the full implementation and the flow of the benefits of these reforms. Thus, the lack of effective governance has deeply weakened their institutions [3] [22] [23]. In countries where the level of effective governance is low, disruptive forces such as corruption tend to flourish and undermine efforts to break the cycle of poverty, underdevelopment, social and economic instability. If this cycle can be broken, then further structural transformations of these economies are possible [4] [24].

The international and transnational dimensions contributing to corruption in Africa call for special attention. It is reported that multinational companies have resorted to corruption in order to avoid taxes, engage in money laundering, seek political influence and legislative favors, avoid import tariffs, and engage in economic rent-seeking in monopolistic and restrictive trade practices. Illicit activities perpetrated by foreigners and foreign companies pose various challenges of administration, law and regulation, enforcement, detection and monitoring. There is also collusion of African elites with foreign networks of corruption. This collusion explains to some degree why a number of structural adjustment programs and policies funded by foreign government and foreign agencies have not resulted in the expected outcome [7] [9]. The aforementioned ills are exacerbated by the conflict of interests with the former colonial powers and developed countries: The interests of African civil societies are subordinated to their own self-interests. For instance, these former colonial powers could make trade, aid and loans subject to progress on effective governance [11] [25] [26].

Therefore, cooperation with disinterested international agencies and foreign governments to curb and eliminate corruption becomes a necessity. The OECD's Anti-Bribery Convention [27] could be used and enforced in order to curb illegal activities by OECD countries and multinationals in Africa. Given the background of OECD's Anti-Bribery Convention, African countries can take better advantage of the US's African Growth and Opportunity Act [28] as "the Act offers tangible incentives for African countries to continue their efforts to open their economies and build free markets" [20] [29]. 


\section{Methodology and Research Design}

Given the discussion in Sections 1 and 2, we posit that as a country moves along the path of economic development the causality question becomes more answerable in the sense of "chicken first or egg first". Our supposition is that corruption within a country coevolves with its economy and governance systems; their evolution, and hence the demand and supply of corruption, is subject to a country's social development and cultural tradition. We would like to refer to this framework as the quintuple helix. At the center of the system are three helices: governance, corruption, and economic development. Accountable governance systems is the pivotal force that curbs corruption and promotes economic development. In the absence of a strong governance system, corruption flourishes and economy stagnates. Corruption, in turns, erodes governance measures and checks economic development, while economic development helps alleviate corruption and leads to effective governance systems. Social development affects and responds to the interactions among governance, corruption, and economic development. For instance, weak economic development results in extraordinary delays in the attainment of generally accepted goals of human development in a just society. All the four helices coevolve within and reshape their cultural environment (Figure 1).

We test the quintuple helix framework of corruption with both a Structural Equation Model (SEM) and a parsimonious OLS regression. Figure 2 provides the path diagram of the Structural Equation Model (SEM) for corruption. This is a theoretical conceptualization of the factors mediating corruption. A few researchers have tried the SEM for corruption and the economy [30] [31]. We base

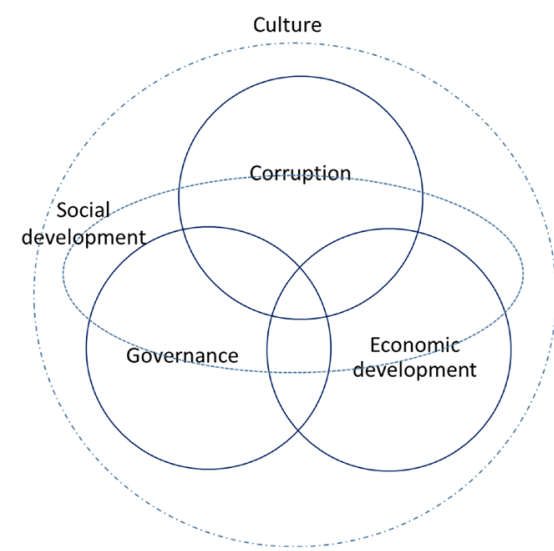

Figure 1. Corruption in a system of quintuple helix. This figure illustrates a quintuple helix system, in which corruption interacts and coevolves with governance, economy, social development, and culture. At the center of the system are three helices: governance, corruption, and economic development. Accountable governance systems is the pivotal force that curbs corruption and promotes economic development. Corruption, in turns, erodes the governance and checks economic development, while economic development helps alleviate corruption and leads to effective governance systems. Social development affects and responds to the interactions among governance, corruption, and economic development, while all the four strands coevolve with their cultural environment. 


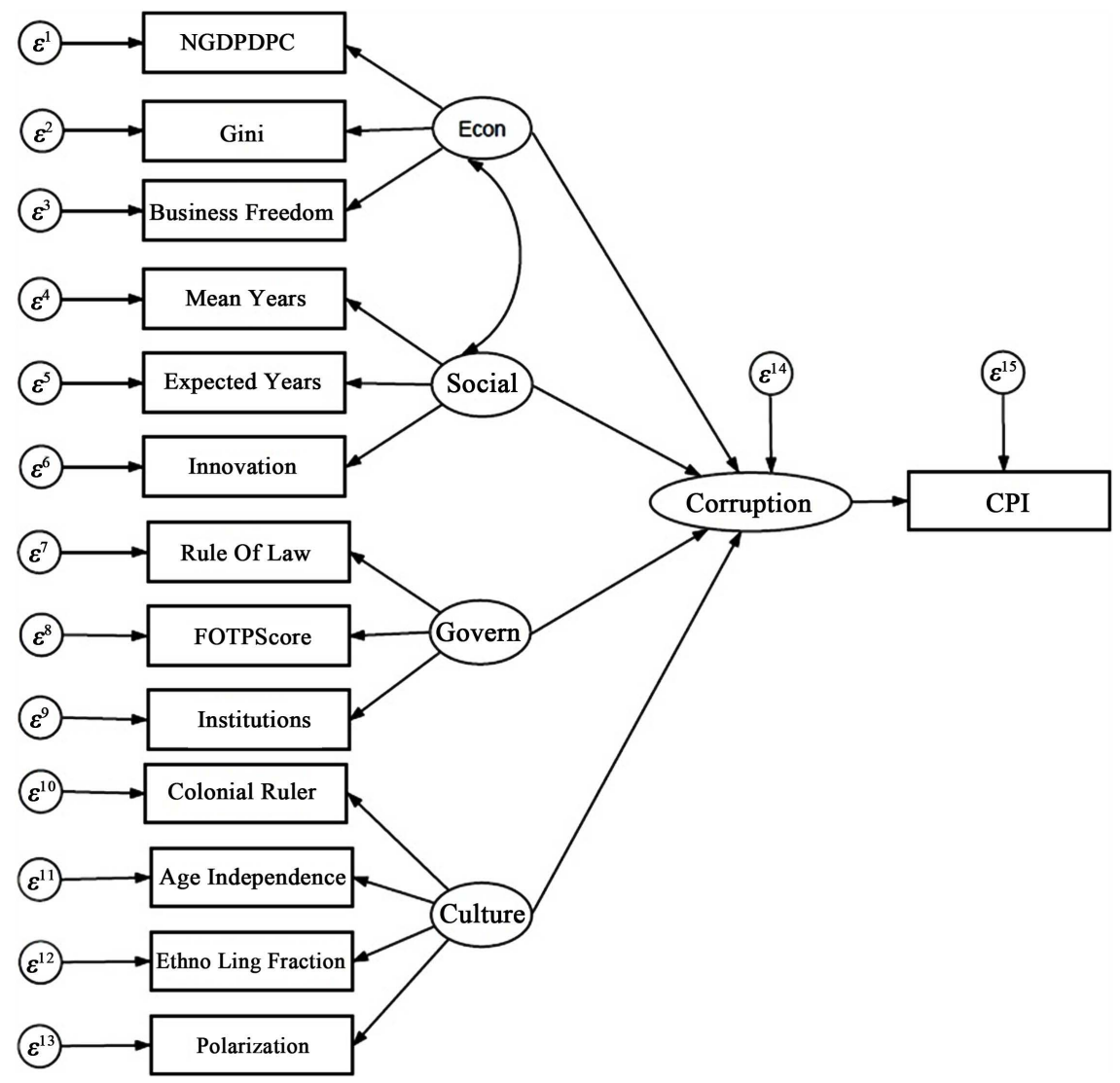

Figure 2. Path diagram for corruption. The latent variable Economic Development consists of NGDPDPC = nominal GDP in USD per capita; Gini = Gini coefficient; and Business Freedom $=$ Freedom of doing business. The latent variable Social Development consists of Mean Year = Mean years of schooling for population; Expected Years = Expected years of schooling for population; and Innovation = Innovation index. The latent variable Governance consists of Rule of Law $=$ Rule of Law index; FOTP Score $=$ Freedom of the Press score; and Institutions = Institution index. The latent variable Culture consists of Colonial Ruler $=$ Which Western European had colonized an African county; Age Independence $=$ Age, in years, since independence from the colonial ruler; Ethno Ling Fraction $=$ Ethno-linguistic fractionalization; and Polarization $=$ Political and cultural polarization.

our SEM of corruption using the detailed study of [32] with robust variables. The latent variable Economic Development consists of NGDPDPC = nominal GDP in USD per capital; Gini = Gini coefficient; and Business Freedom $=$ Freedom of doing business. The latent variable Social Development consists of Mean Year $=$ Mean years of schooling for the population; Expected Years $=$ Expected years of schooling for population; and Innovation = Innovation index. The latent variable Governance consists of Rule of Law = Rule of Law index; FOTP Score $=$ Freedom of the Press score; and Institutions = Institution index. The latent variable Culture consists of Colonial Ruler $=$ Which Western European country had colonized an African country; Age Independence = Age, in years, since independence from the colonial ruler; Ethno Ling Fraction $=$ Ethno-linguistic fractionalization; and Polarization = Political and cultural polariza- 
tion. These latent variables mediate the actual corruption level measured by CPI, an indicator of political corruption and bureaucratic corruption, published by Transparency International.

Since SEM requires a large dataset, which is inherently difficult to obtain for a cross-country study with a focus on Africa, we resort to a parsimonious OLS model to test the quintuple helix framework:

$$
\begin{aligned}
\text { Corruption }_{i}= & \alpha+\beta_{1} \text { Eco_stage }_{i}+\beta_{2} G D P_{-} P P P_{i}+\beta_{3} \text { Institutions }_{i} \\
& +\beta_{4} \text { Press_freedom }_{i}+\beta_{5} \text { ELF }_{i}+\beta_{6} H D I_{i}+\varepsilon_{i}
\end{aligned}
$$

where Eco_stage and GDP_PPP are proxies for economic development, Institutions and Press_freedom for governance systems, ELF for cultural environment, and $H D I$ for social development.

More specifically, Eco_stage is the stage of development based on the World Economic Forum's Global Competitiveness Report 2017-2018, coded 1, 3, and 5 for factor-driven, efficiency-driven, and innovation-driven economies, respectively; it is coded 2 for economies in transition from factor-driven to efficiency-driven and 4 for economies in transition from efficiency-driven to innovation-driven. GDP_PPP is the 2016 GDP per capita based on purchasing power parity (PPP) in 2011 international dollars published by the World Bank. Institutions is the index of institutions as a component of the Global Innovation Index of 2015, covering a country's political, regulatory, and business environment. The country with the strongest institutions ranks first. Press_freedom is the press freedom index of 2015 compiled and published by Reporters Without Borders. The country with the highest level of press freedom ranks first. $E L F$ is the Ethno-linguistic fractionalization score between 0 (zero fractionalization) and 1 (highest fractionalization) based on the work of [33] [34] and [35]. HDI is the Human Development Index based on the United Nations Human Development Reports of 2016. It is a composite index measuring average achievement in three basic dimensions of human development-a long and healthy life, knowledge, and a decent standard of living. The country with the highest human development ranks first. We multiply the original numerical ranks of press freedom, institutions, and HDI by -1 , so that a greater value denotes greater press freedom, stronger institutions, and higher level of human development. We argue that corruption within a country coevolves with its governance systems such that effective governance constrains corruption but rampant corruption erodes governance. Similarly, corruption slows down a country's social development, while a developed society stunts the demand and supply of corruption. Under these arguments, we expect negative correlations between corruption and the transformed variables of Institutions, Press_freedom, and HDI.

With regard to the dependent variable, we recognize that corruption has many dimensions and comes in different shapes and forms. Given corruption's shady and secret nature, measuring corruption is not an easy task. We employ three measures of corruption: 1) TI_CPI, the Corruption Perception Index of 2017 published by Transparency International. It ranks countries by their "perceived 
levels of public sector corruption as determined by expert assessments and opinion surveys." The country with the lowest perceived level of corruption ranks first; 2) WB_briberyl, the bribery incidence measured with the percent of firms experiencing at least one bribe payment request across six public transactions dealing with utilities access, permits, licenses, and taxes, based on [36]; 3) WB_bribery2, the percent of firms identifying corruption as a major constraint, also based on [36].

Most data are from 2015 or 2016. Not all measurements are undertaken every year. Thus, if a variable did not have the most current data, we used the last available data. In various specifications of the tests, when an observation (country) misses the data required to compute a variable in the model, the observation is dropped. See the Appendix for more details about the variables.

\section{Results and Analysis}

We mentioned earlier that various strands of research suggest that the stage of development and corruption have negative correlation, i.e., higher the development, lower is the corruption. Figure 3 and Figure 4 illustrate the negative relationship between CPI and different levels and stages of economic development. The CPI ranks are plotted for countries grouped by the stage of economic development: factor-driven economies (Stage 1), economies in transition from Stage 1 to Stage 2, efficiency-driven economies (Stage 2), economies in transition from Stage 2 to Stage 3, and innovation-driven economies (Stage 3). Figure 3 is constructed with all countries with available data, and Figure 4, with African countries only. In both cases, the bivariate plots show that as a country moves

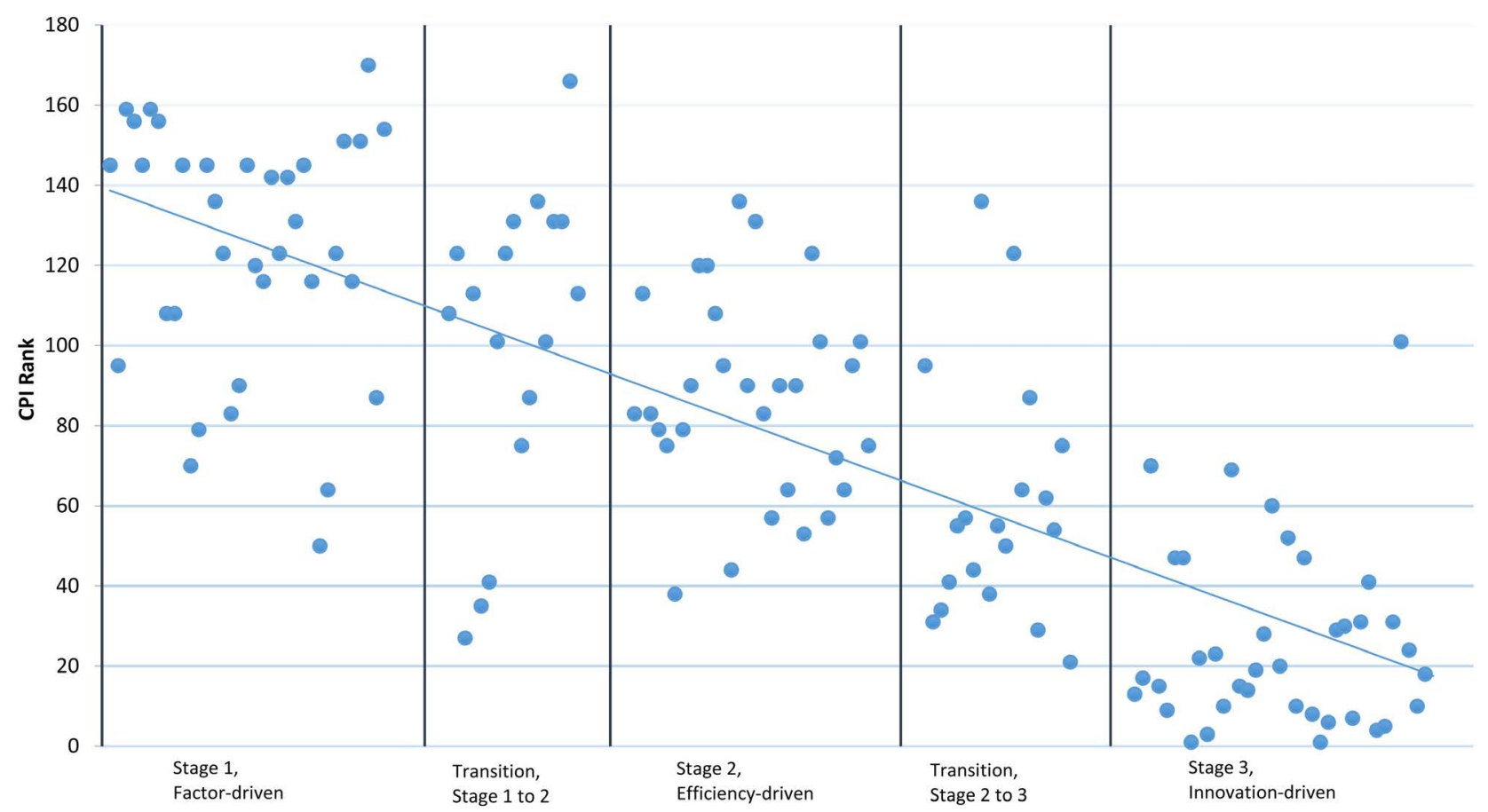

Figure 3. CPI rank vs. stage of economic development. 


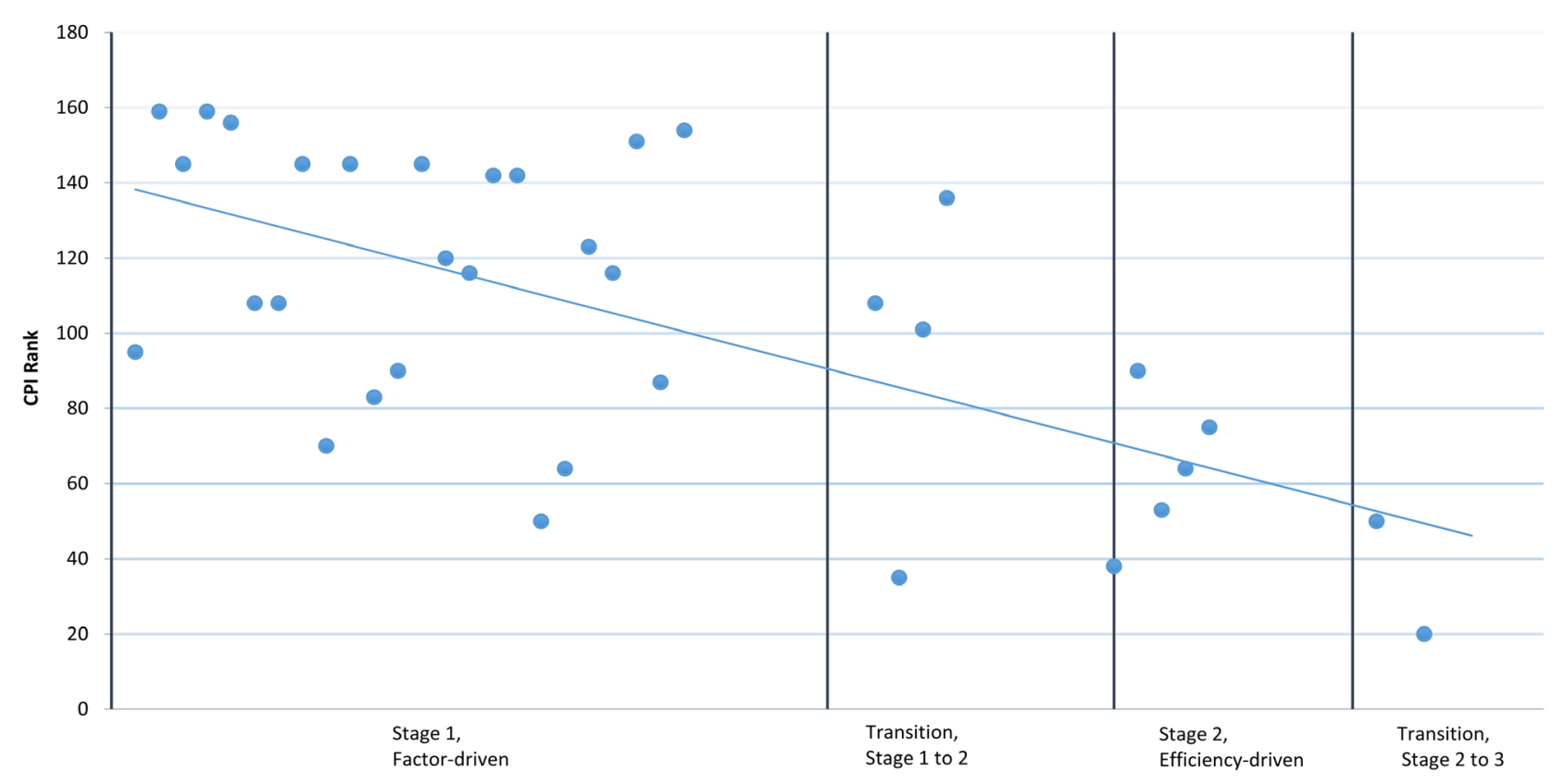

Figure 4. CPI rank vs. stage of economic development: Africa.

away from resource-driven towards innovation-driven economy it becomes less plagued by corruption.

Table 1 reports the descriptive statistics of the variables used in the OLS tests. Note that Institutions, Press_freedom, and HDI all have negative values because we have transformed the original ranks by multiplying with -1 so that a larger value corresponds to a better state of institutions, press freedom, or human development. Panel A shows the statistics for the full sample, in which not all countries have the measurement for stage of economic development. Panel B shows the statistics for African countries only. For 46 African countries, we are able to collect data for most of the variables except for stage of economic development. A comparison of the statistics in the two panels indicate that the African countries face more severe corruption, with higher median values for all the three measures: 121.5 for $T I \_C P I, 21.5$ for $W B_{-}$briberyl, and 41.5 for $W B \_$bribery2, while the corresponding values of corruption measures for the full sample are 90, 11.1, and 27.9. In terms of economic development, the median African country is a resource-driven economy (stage 1) with \$2667 annual GDP per capita, while a median country of the world is an efficiency-driven economy with $\$ 13,012$ annual GDP per capita. African countries also appear to lag behind the world in governance and social development, with median values of Institutions, Press_freedom, and $H D I$ all lower than that of the full sample: -118.5 , -105 , and -159.5 for Africa and $-83,-93$, and -90 for the world. The $E L F$ measure reveals that an average African country (with median ELF of 0.55 ) is more ethnically heterogeneous than an average country in other parts of the world (with median $E L F$ of 0.38 ).

Table 2 shows the bivariate correlation of the variables. TI_CPI, $W B \_$briberyl, and $W B_{-}$bribery 2 are all positively correlated, suggesting they 
Table 1. Descriptive statistics of variables.

(a) Full sample

\begin{tabular}{lccccccc}
\hline Variable & N & Minimum & Q2 & Median & Q3 & Maximum & Mean \\
\hline TI_CPI & 157 & 1 & 47 & 90 & 131 & 175 & 88.21 \\
WB_bribery1 & 157 & 0 & 3.9 & 11.1 & 23.8 & 64.7 & 16.11 \\
WB_bribery2 & 157 & 0 & 11 & 27.9 & 49.4 & 97.4 & 31.87 \\
Eco_stage & 132 & 1 & 1.5 & 3 & 5 & 5 & 3.05 \\
GDP_PPP & 155 & 607.17 & 4063.96 & $13,012.18$ & $26,974.63$ & $143,426.98$ & $18,938.35$ \\
Institutions & 157 & -142 & -123 & -83 & -42 & -1 & -81.17 \\
Press_freedom & 157 & -180 & -134 & -93 & -46 & -1 & -89.86 \\
ELF & 157 & 0 & 0.135 & 0.3763 & 0.6638 & 0.9841 & 0.40 \\
HDI & 157 & -188 & -144 & -90 & -44 & -1 & -93.33 \\
\hline
\end{tabular}

(b) African countries

\begin{tabular}{|c|c|c|c|c|c|c|c|}
\hline Variable & $\mathbf{N}$ & Minimum & Q2 & Median & Q3 & Maximum & Mean \\
\hline$T I \_C P I$ & 46 & 35 & 87 & 121.5 & 153 & 175 & 117.30 \\
\hline WB_briberyl & 46 & 0 & 10.3 & 21.5 & 28.9 & 56.5 & 22.21 \\
\hline WB_bribery2 & 46 & 0 & 29.8 & 41.5 & 54.1 & 75.6 & 41.52 \\
\hline Eco_stage & 33 & 1 & 1 & 1 & 2 & 4 & 1.58 \\
\hline$G D P \_P P P$ & 45 & 607.17 & 1548.2 & 2666.71 & 6559.28 & $22,924.15$ & 5130.10 \\
\hline Institutions & 46 & -142 & -142 & -118.5 & -90 & -23 & -111.41 \\
\hline Press_freedom & 46 & -180 & -131 & -105 & -65 & -17 & -101.63 \\
\hline$E L F$ & 46 & 0 & 0.0699 & 0.55455 & 0.7348 & 0.9483 & 0.46 \\
\hline$H D I$ & 46 & -188 & -176 & -159.5 & -135 & -64 & -151.78 \\
\hline
\end{tabular}

See Appendix for the definition of the variables.

Table 2. Pearson correlation coefficients of variables.

\begin{tabular}{|c|c|c|c|c|c|c|c|c|c|}
\hline & \multicolumn{9}{|c|}{ Prob $>|\rho|$ under $\mathrm{H}_{0}: \rho=0$} \\
\hline & $T I \_C P I$ & WB_briberyl & WB_bribery2 & Eco_stage & $G D P \_P P P$ & Institution & Press_freedom & $E L F$ & $H D I$ \\
\hline$T I \_C P I$ & 1.000 & & & & & & & & \\
\hline \multirow{2}{*}{$W B \_b r i b e r y 1$} & 0.632 & 1.000 & & & & & & & \\
\hline & $<0.0001$ & & & & & & & & \\
\hline \multirow{2}{*}{ WB_bribery2 } & 0.531 & 0.543 & 1.000 & & & & & & \\
\hline & $<0.0001$ & $<0.0001$ & & & & & & & \\
\hline \multirow{2}{*}{ Eco_stage } & -0.793 & -0.6400 & -0.4600 & 1.000 & & & & & \\
\hline & $<0.0001$ & $<0.0001$ & $<0.0001$ & & & & & & \\
\hline \multirow{2}{*}{$G D P \_P P P$} & -0.665 & -0.3490 & -0.2820 & 0.733 & 1.000 & & & & \\
\hline & $<0.0001$ & $<0.0001$ & 0.000 & $<0.0001$ & & & & & \\
\hline \multirow{2}{*}{ Institutions } & -0.872 & -0.5760 & -0.5870 & 0.822 & 0.686 & 1.000 & & & \\
\hline & $<0.0001$ & $<0.0001$ & $<0.0001$ & $<0.0001$ & $<0.0001$ & & & & \\
\hline \multirow{2}{*}{ Press_freedom } & -0.635 & -0.4650 & -0.3390 & 0.509 & 0.314 & 0.616 & 1.000 & & \\
\hline & $<0.0001$ & $<0.0001$ & $<0.0001$ & $<0.0001$ & $<0.0001$ & $<0.0001$ & & & \\
\hline \multirow{2}{*}{$E L F$} & 0.212 & 0.313 & 0.176 & -0.2270 & -0.0700 & -0.2770 & -0.2930 & 1.000 & \\
\hline & 0.008 & $<0.0001$ & 0.028 & 0.009 & 0.389 & 0.000 & 0.000 & & \\
\hline \multirow{2}{*}{$H D I$} & -0.776 & -0.5510 & -0.5130 & 0.917 & 0.765 & 0.823 & 0.437 & -0.3060 & 1.000 \\
\hline & $<0.0001$ & $<0.0001$ & $<0.0001$ & $<0.0001$ & $<0.0001$ & $<0.0001$ & $<0.0001$ & $<0.0001$ & \\
\hline
\end{tabular}

See Appendix for the definition of the variables. 
capture something common in corruption. They are negatively correlated with measures of economic development (i.e. Eco_stage and GDP_PPP), governance (i.e. Institutions and Press_freedom), and social development (HDI) but positively correlated with cultural diversity $(E L F)$. This pattern is consistent with the argument that a country's economic, political, social and cultural environments all have an effect on its corruption. For instance, effective governance, such as strong institutions and press freedom, contains corruptive practices; high social development suppresses the demand and supply of corruption. In other words, in a country with better governance and more developed society, we should observe fewer instances of corruption. However, more interestingly, these factors also highly correlate with one another, suggesting a strong interdependence. In fact, only one pair does not show significant correlation: ELF and GDP_PPP.

Table 3 presents the results from multiple regressions run on the full sample. It tests the relationship between economic development, proxied by Eco_stage and $G D P \_P P P$, and perceived level of corruption, proxied by $T I \_C P I$, across all the sample countries. The results indicate that, in the presence of controls for governance (proxied by Institutions and Press_freedom), culture (proxied by $E L F)$, and social development (proxied with $H D I$ ), both Eco_stage and $G D P \_P P P$ are significant in explaining the variation in perceived level of corruption, with coefficient estimates to be -7.473 (p-value 0.021) and -6.910 (p-value 0.033), respectively. However, when both Eco_stage and GDP_PPP are included in the same model, the coefficient on GDP_PPPis not significant anymore.

In Table 4, we report the multivariate tests of the relationship between economic development and actual level of corruption across countries. In Panel A,

Table 3. Perceived corruption and economic development.

TI_CPI $=\alpha+\beta_{1} E_{i} c o \_$stage $_{i}+\beta_{2} G D P \_P P P_{i}+\beta_{3}$ Institutions $_{i}+\beta_{4}$ Press_freedom $_{i}+\beta_{5}$ ELF $_{i}+\beta_{6} H D I_{i}+\varepsilon_{i}$.

\begin{tabular}{|c|c|c|c|c|c|c|c|c|c|}
\hline Variable & Parameter & SE & $\operatorname{Pr}>|t|$ & Parameter & SE & $\operatorname{Pr}>|t|$ & Parameter & SE & $\operatorname{Pr}>|t|$ \\
\hline Intercept & 46.681 & 17.552 & 0.009 & 51.961 & 17.913 & 0.004 & 52.737 & 16.722 & 0.002 \\
\hline Eco_stage & -7.473 & 3.186 & 0.021 & & & & -7.361 & 2.999 & 0.015 \\
\hline$G D P \_P P P$ & & & & -6.910 & 3.201 & 0.033 & 0.000 & 0.000 & 0.220 \\
\hline Institutions & -0.676 & 0.092 & $<0.0001$ & 0.000 & 0.000 & 0.174 & -0.695 & 0.090 & $<0.0001$ \\
\hline Press_freedom & -0.159 & 0.050 & 0.002 & -0.652 & 0.094 & $<0.0001$ & -0.165 & 0.048 & 0.001 \\
\hline$E L F$ & -14.591 & 7.067 & 0.041 & -0.168 & 0.050 & 0.001 & -12.796 & 6.985 & 0.069 \\
\hline \multirow[t]{2}{*}{$H D I$} & 0.011 & 0.093 & 0.906 & -12.041 & 7.285 & 0.101 & 0.070 & 0.089 & 0.434 \\
\hline & & & & 0.04604 & 0.09602 & 0.6324 & & & \\
\hline Adj. R-squared & 0.7982 & & & 0.7898 & & & 0.7996 & & \\
\hline$N$ & 132 & & & 155 & & & 132 & & \\
\hline
\end{tabular}

This table tests the relationship between economic development, proxied by Eco_stage and GDP_PPP, and perceived level of corruption across countries. The results indicate that, in the presence of controls for governance (proxied by Institutions and Press_freedom), culture, and social development, economic development, especially proxied with Eco_stage, is significant in explaining the variation in perceived level of corruption. P-values are reported for two-tailed tests. See Appendix for the definition of the variables. 
Table 4. Actual corruption and economic development.

(a) WB_bribery $1_{i}=\alpha+\beta_{1} E c o \_$stage $_{i}+\beta_{2} G D P_{-} P P P_{i}+\beta_{3}$ Institutions $_{i}+\beta_{4}$ Press freedom $_{i}+\beta_{5}$ ELF $_{i}+\beta_{6} H D I_{i}+\varepsilon_{i}$

\begin{tabular}{|c|c|c|c|c|c|c|c|c|c|}
\hline Variable & Parameter & SE & $\operatorname{Pr}>|t|$ & Parameter & SE & $\operatorname{Pr}>|t|$ & Parameter & SE & $\operatorname{Pr}>|t|$ \\
\hline Intercept & 13.685 & 8.653 & 0.116 & -7.118 & 3.838 & 0.066 & 9.880 & 8.755 & 0.261 \\
\hline Eco_stage & -3.446 & 1.570 & 0.030 & & & & -3.851 & 1.565 & 0.015 \\
\hline$G D P \_P P P$ & & & & 0.000 & 0.000 & 0.159 & 0.000 & 0.000 & 0.046 \\
\hline Institutions & -0.065 & 0.046 & 0.156 & -0.085 & 0.042 & 0.047 & -0.082 & 0.046 & 0.074 \\
\hline Press_freedom & -0.042 & 0.024 & 0.090 & -0.048 & 0.023 & 0.042 & -0.035 & 0.024 & 0.153 \\
\hline$E L F$ & 10.077 & 3.484 & 0.005 & 4.746 & 3.560 & 0.185 & 8.240 & 3.561 & 0.022 \\
\hline$H D I$ & -0.002 & 0.046 & 0.968 & -0.087 & 0.035 & 0.014 & -0.027 & 0.047 & 0.565 \\
\hline Adj. $R$-squared & 0.484 & & & 0.3681 & & & 0.4962 & & \\
\hline$N$ & 132 & & & 155 & & & 132 & & \\
\hline
\end{tabular}

This table tests the relationship between economic development, proxied by Eco_stage and GDP_PPP, and actual level of corruption across countries. Corruption is proxied with WB_briberyl. The results indicate that, in the presence of controls for governance (proxied by Institutions and Press_freedom), culture, and social development, Eco_stage is still significant in explaining the variation in the incidence of briberies, but $G D P \_P P P$ is not. When both Eco_stage and GDP_PPP are in the model, the loading on GDP_PPP is significantly positive, contrary to the conventional belief that economic development constrains corruption. Compared to Table 3, the R-squares also drop substantially. P-values are reported for two-tailed tests. See Appendix for the definition of the variables.

(b) WB bribery $2_{i}=\alpha+\beta_{1} E_{\text {co stage }}+\beta_{2} G D P P P P_{i}+\beta_{3}$ Institutions $_{i}+\beta_{4}$ Press freedom $_{i}+\beta_{5}$ ELF $_{i}+\beta_{6} H D I_{i}+\varepsilon_{i}$

\begin{tabular}{|c|c|c|c|c|c|c|c|c|c|}
\hline Variable & Parameter & SE & $\operatorname{Pr}>|t|$ & Parameter & SE & $\operatorname{Pr}>|t|$ & Parameter & SE & $\operatorname{Pr}>|t|$ \\
\hline Intercept & -13.733 & 13.559 & 0.313 & -6.571 & 5.467 & 0.231 & -23.609 & 13.324 & 0.079 \\
\hline Eco_stage & 4.126 & 2.461 & 0.096 & & & & 3.074 & 2.381 & 0.199 \\
\hline$G D P \_P P P$ & & & & 0.000 & 0.000 & 0.000 & 0.000 & 0.000 & 0.001 \\
\hline Press_freedom & -0.010 & 0.038 & 0.793 & 0.021 & 0.033 & 0.530 & 0.007 & 0.037 & 0.843 \\
\hline$E L F$ & 1.046 & 5.459 & 0.848 & -3.962 & 5.071 & 0.436 & -3.725 & 5.419 & 0.493 \\
\hline$H D I$ & -0.103 & 0.072 & 0.153 & -0.123 & 0.049 & 0.014 & -0.169 & 0.071 & 0.020 \\
\hline Adj. $R$-squared & 0.3545 & & & 0.3811 & & & 0.4056 & & \\
\hline$N$ & 132 & & & 155 & & & 132 & & \\
\hline
\end{tabular}

This table tests the relationship between economic development, proxied by Eco_stage and GDP_PPP, and actual level of corruption across countries. Corruption is proxied with WB_bribery2. The results indicate that, in the presence of controls for governance (proxied by Institutions and Press_freedom), culture (proxied by $E L F$ ), and social development (proxied with $H D I$ ), neither Eco_stage nor GDP_PPP is significant in explaining the variation in firms' assessment of the severity of corruption in the predicted direction. The loading on GDP_PPP even turns significantly positive, contrary to the conventional belief that economic development constrains corruption. Compared to Table 3, the R-squares also drop substantially. P-values are reported for two-tailed tests. See Appendix for the definition of the variables.

corruption is proxied with $W B \_b r i b e r y l$. In Panel $\mathrm{B}$, corruption is proxied with $W B \_$bribery2. The results indicate that, in the presence of controls for governance (Institutions and Press_freedom), culture (ELF), and social development (HDI), Eco_stage is significant in explaining the variation in WB_briberyl, but not $W B_{-}$bribery2. $G D P_{-} P P P$ is either insignificant or loaded significantly posi- 
tive, contrary to the conventional belief that economic development constrains corruption. In contrast, the governance measure Institutions is consistently negative at significant levels, confirming that a country with strong institutions experience less corruption. Compared to Table 3, the r-squares also drop substantially, suggesting that actual level of corruption results from more complex factors than perceived corruption. Overall, these patterns indicate that the negative relationship observed between corruption and economic development may be driven largely by some common factors related to a country's political or governance systems.

Table 5 and the two panels of Table 6 show the results from the subsample of African countries when corruption is proxied by $T I_{-} C P I, W B_{-}$briberyl and WB_bribery2 alternatively. In Table 5, neither Eco_stagenor GDP_PPP is significant in explaining the variation in TI_CPI. The two governance measures (Institutions and Press_freedom) are still consistently significant and having the expected sign. However, Panel B of Table 6 reveals that neither Eco_stage nor $G D P \_P P P$, by itself or together, is significant in explaining $W B_{-}$bribery2, the percent of firms experiencing bribe payment request, or $W B \_b r i b e r y 2$, the percent of firms identifying corruption as a major constraint. The only variable statistically significant is Institutions. Taken together, these results indicate that the effect of economic development on corruption is minimal in Africa, where the most salient driving force of both corruption and economic growth is institutions that defines a country's political, regulatory and business environment.

Since the estimates drawn from the OLS regressions on cross-sectional data can suffer from statistical inefficiency because of nonspherical error terms, we undertake heteroscedasticity tests on three specifications of the model with both

Table 5. Perceived corruption and economic development-Africa.

\begin{tabular}{|c|c|c|c|c|c|c|c|c|c|}
\hline Variable & Parameter & SE & $\operatorname{Pr}>|t|$ & Parameter & SE & $\operatorname{Pr}>|t|$ & Parameter & SE & $\operatorname{Pr}>|t|$ \\
\hline Intercept & -0.636 & 56.674 & 0.991 & 21.213 & 49.157 & 0.669 & 18.111 & 71.868 & 0.803 \\
\hline Eco_stage & -3.804 & 10.026 & 0.707 & & & & -2.875 & 10.401 & 0.784 \\
\hline$G D P \_P P P$ & & & & -0.001 & 0.002 & 0.457 & -0.001 & 0.002 & 0.667 \\
\hline Institutions & -0.533 & 0.195 & 0.011 & -0.759 & 0.159 & $<0.0001$ & -0.558 & 0.207 & 0.012 \\
\hline Press_freedom & -0.183 & 0.129 & 0.166 & -0.212 & 0.100 & 0.040 & -0.176 & 0.132 & 0.193 \\
\hline$E L F$ & 0.250 & 15.522 & 0.987 & -6.985 & 12.555 & 0.581 & 0.030 & 15.768 & 0.999 \\
\hline$H D I$ & -0.281 & 0.286 & 0.335 & 0.009 & 0.305 & 0.976 & -0.161 & 0.400 & 0.692 \\
\hline Adj. $R$-squared & 0.5277 & & & 0.5936 & & & 0.5131 & & \\
\hline$N$ & 33 & & & 45 & & & 33 & & \\
\hline
\end{tabular}

This table tests the relationship between economic development, proxied by Eco_stage and GDP_PPP, and perceived level of corruption across African countries. The results indicate that, in the presence of controls for governance (proxied by Institutions and Press_freedom), culture, and social development, neither Eco_stage or GDP_PPP is significant in explaining the variation in perceived level of corruption at conventional level. In contrast, a governance measure, Institutions, is consistently significant in explaining the variation in corruption. P-values are reported for two-tailed tests. See Appendix for the definition of the variables. 
Table 6. Actual corruption and economic development-Africa.

(a) WB_bribery $1_{j}=\alpha+\beta_{1} E c o \_$stage $e_{j}+\beta_{2} G D P P_{-} P P P_{j}+\beta_{3}$ Institutions $_{j}+\beta_{4}$ Press freedom $_{j}+\beta_{5} E L F_{j}+\beta_{6} H D I_{j}+\varepsilon_{j}$

\begin{tabular}{|c|c|c|c|c|c|c|c|c|c|}
\hline Variable & Parameter & SE & $\operatorname{Pr}>|t|$ & Parameter & SE & $\operatorname{Pr}>|t|$ & Parameter & SE & $\operatorname{Pr}>|t|$ \\
\hline Intercept & -17.437 & 19.252 & 0.373 & 11.630 & 24.664 & 0.640 & -16.786 & 24.501 & 0.499 \\
\hline Eco_stage & 0.032 & 3.406 & 0.993 & & & & 0.065 & 3.546 & 0.986 \\
\hline$G D P \_P P P$ & & & & 0.000 & 0.001 & 0.568 & 0.000 & 0.001 & 0.965 \\
\hline Institutions & -0.188 & 0.066 & 0.009 & -0.220 & 0.080 & 0.009 & -0.189 & 0.070 & 0.013 \\
\hline Press_freedom & -0.026 & 0.044 & 0.559 & 0.004 & 0.050 & 0.929 & -0.026 & 0.045 & 0.574 \\
\hline$E L F$ & 13.395 & 5.273 & 0.017 & 3.620 & 6.299 & 0.569 & 13.388 & 5.376 & 0.020 \\
\hline$H D I$ & -0.087 & 0.097 & 0.376 & 0.088 & 0.153 & 0.569 & -0.083 & 0.136 & 0.547 \\
\hline Adj. R-squared & 0.5548 & & & 0.1581 & & & 0.5377 & & \\
\hline$N$ & 33 & & & 45 & & & 33 & & \\
\hline
\end{tabular}

This table tests the relationship between economic development, proxied by Eco_stage and GDP_PPP, and actual level of corruption across African countries. Corruption is proxied with WB_briberyl. The results indicate that, in the presence of controls for governance (proxied by Institutions and Press_freedom), culture (proxied with ELF), and social development (proxied with $H D I$ ), neither Eco_stage nor GDP_PPP is significant in explaining the variation in the incidence of briberies. In contrast, one of the governance measures, Institutions, is consistently significant in explaining the variation in corruption. Compared to Table 5, the R-squared also drop substantially. P-values are reported for two-tailed tests. See Appendix for the definition of the variables.

(b) WB_bribery $2_{j}=\alpha+\beta_{1} E c o \_$stage $e_{j}+\beta_{2} G D P P_{-} P P P_{j}+\beta_{3}$ Institutions $_{j}+\beta_{4}$ Press_freedom $_{j}+\beta_{5} E L F_{j}+\beta_{6} H D I_{j}+\varepsilon_{j}$

\begin{tabular}{|c|c|c|c|c|c|c|c|c|c|}
\hline Variable & Parameter & SE & $\operatorname{Pr}>|t|$ & Parameter & SE & $\operatorname{Pr}>|t|$ & Parameter & SE & $\operatorname{Pr}>|t|$ \\
\hline Intercept & 1.488 & 30.502 & 0.962 & 32.525 & 32.485 & 0.323 & 10.819 & 38.701 & 0.782 \\
\hline Eco_stage & 6.087 & 5.396 & 0.269 & & & & 6.549 & 5.601 & 0.253 \\
\hline$G D P \_P P P$ & & & & 0.000 & 0.001 & 0.848 & 0.000 & 0.001 & 0.691 \\
\hline Institutions & -0.312 & 0.105 & 0.006 & -0.287 & 0.105 & 0.010 & -0.325 & 0.111 & 0.007 \\
\hline Press_freedom & -0.026 & 0.069 & 0.715 & 0.034 & 0.066 & 0.613 & -0.022 & 0.071 & 0.758 \\
\hline$E L F$ & 3.244 & 8.354 & 0.701 & 2.500 & 8.297 & 0.765 & 3.135 & 8.491 & 0.715 \\
\hline$H D I$ & 0.051 & 0.154 & 0.742 & 0.143 & 0.201 & 0.483 & 0.111 & 0.216 & 0.611 \\
\hline Adj. R-squared & 0.210 & & & 0.094 & & & 0.185 & & \\
\hline$N$ & 33 & & & 45 & & & 33 & & \\
\hline
\end{tabular}

This table tests the relationship between economic development, proxied by Eco_stage and GDP_PPP, and actual level of corruption across African countries. Corruption is proxied with $W B_{-}$bribery2. The results indicate that, in the presence of controls for governance (proxied by Institutions and Press_freedom), culture (proxied by $E L F$ ), and social development (proxied with $H D I$ ), neither Eco_stage nor GDP_PPP is significant in explaining the variation in firms' assessment of the severity of corruption. In contrast, one of the governance measures, Institutions, is consistently significant in explaining the variation in corruption. Compared to Table 5, the R-squares also drop substantially. P-values are reported for two-tailed tests. See Appendix for the definition of the variables.

the full sample and the Africa subsample. Table 7 reports the results from White's test and Breusch-Pagan test. As shown in Panel A, when applied to the Africa subsample, the p-values from both tests on all the specifications are greater than $10 \%$. The results fail to reject the null hypothesis that the error terms in OLS tests run on the Africa subsample are homoscedastic. Panel B reports the test statistics on the full sample. The results suggest that OLS regressions 
Table 7. Heteroscedasticity test.

(a)

\begin{tabular}{lllcll}
\hline Dependent Variable & Sample & Test & Statistic & $\operatorname{Pr}>\chi^{2}$ & Variables \\
\hline \multirow{2}{*}{ TI_CPI } & Africa & White's Test & 24.43 & 0.2242 & Cross of all variables \\
& & Breusch-Pagan & 5 & 0.1382 & 1, Eco_stage, Institutions, Press_freedom, ELF, HDI \\
WB_bribery1 & Africa & White's Test & 17.21 & 0.6393 & Cross of all variables \\
& & Breusch-Pagan & 7.71 & 0.173 & 1, Eco_stage, Institutions, Press_freedom, ELF, HDI \\
WB_bribery2 & Africa & White's Test & 18.72 & 0.5402 & Cross of all variables \\
& & Breusch-Pagan & 4.18 & 0.5232 & 1, Eco_stage, Institutions, Press_freedom, ELF, HDI
\end{tabular}

(b)

\begin{tabular}{lllcll}
\hline Dependent Variable & Sample & Test & Statistic & $\operatorname{Pr}>\chi^{2}$ & Variables \\
\hline \multirow{2}{*}{ TI_CPI } & Full & White's Test & 56.55 & $<0.0001$ & Cross of all variables \\
& & Breusch-Pagan & 14.33 & 0.0136 & 1, Eco_stage, Institutions, Press_freedom, ELF, HDI \\
WB_bribery1 & Full & White's Test & 22.48 & 0.3149 & Cross of all variables \\
& & Breusch-Pagan & 12.95 & 0.0238 & 1, Eco_stage, Institutions, Press_freedom, ELF, HDI \\
WB_bribery2 & Full & White's Test & 39.67 & 0.0055 & Cross of all variables
\end{tabular}

This table tests whether any of the three specifications of the OLS model may suffer from heteroscedasticity. Panel A reports the results when the tests are applied to the Africa subsample, and Panel B, the full sample. The results do not reveal heteroscedasticity problems for OLS tests on the Africa subsample. However, the OLS tests run on the full sample, especially with TI_CPI or WB_bribery2 as dependent variable, may have lost efficiency due to heteroscedasticity. P-values are reported for two-tailed tests based on robust errors. See Appendix for the definition of the variables.

with TI_CPIor WB_bribery2 as dependent variable may have lost efficiency due to heteroscedasticity. The results on $W B \_$briberyl are mixed.

Despite the mixed results from the White and Breusch-Pagan tests, for robustness check, we rerun the three specifications of the model with $M$ estimation [37]. The robust regression produces maximum likelihood estimates to mitigate the influence of outliers. Table 8 and Table 9 summarize the robustness tests on the full sample and the Africa subsample, respectively. Tests presented in Table 8 on the full sample confirm that $G D P_{-} P P P$, either by itself or in combination with Eco_stage, is not significant in explaining the variability in perceived or actual experience of corruption in multiple regressions. Eco_stage is significant in explaining the variation in $T I \_C P I$ and $W B \_b r i b e r y 1$ but not WB_bribery2. Results from the Africa sample (Table 9) also confirm the OLS finding that Eco_stage is only significant in explaining the variation of $W B_{-}$briberyl, but not TI_CPI or WB_bribery2. In contrast, governance, especially measured with Institutions, is consistently significant in explaining the variation in both perceived and actual corruption. In summary, the robustness tests confirm the results of OLS regressions. 
Table 8. Corruption and economic development - robustness tests. Corruption $_{i}=\alpha+\beta_{1}$ Eco_stage $_{i}+\beta_{2} G D P \_P P P_{i}+\beta_{3}$ Institutions $_{i}$

$+\beta_{4}$ Press_freedom ${ }_{i}+\beta_{5} E L F_{i}+\beta_{6} H D I_{i}+\varepsilon_{i}$

(a) Dependent variable: TI_CPI

\begin{tabular}{lcccccc}
\hline Variable & Parameter & $\operatorname{Pr}>\chi^{2}$ & Parameter & $\operatorname{Pr}>\chi^{2}$ & Parameter & $\operatorname{Pr}>\chi^{2}$ \\
\hline Intercept & 55.926 & 0.002 & 13.082 & 0.084 & 60.851 & 0.001 \\
Eco_stage & -9.322 & 0.004 & & & -8.783 & 0.007 \\
GDP_PPP & & & 0.000 & 0.173 & 0.000 & 0.204 \\
Institutions & -0.603 & $<0.0001$ & -0.677 & $<0.0001$ & -0.570 & $<0.0001$ \\
Press_freedom & -0.174 & 0.001 & -0.208 & $<0.0001$ & -0.187 & 0.000 \\
ELF & -17.076 & 0.017 & -15.772 & 0.025 & -14.279 & 0.053 \\
HDI & -0.010 & 0.915 & -0.134 & 0.049 & 0.018 & 0.853 \\
$R$-squared & 0.7221 & & 0.7266 & & 0.7233 & \\
$\boldsymbol{N}$ & 132 & & 155 & & 132 & \\
\hline
\end{tabular}

(b) Dependent variable: WB_bribery1

\begin{tabular}{lcccccc}
\hline Variable & Parameter & $\operatorname{Pr}>\chi^{2}$ & Parameter & $\operatorname{Pr}>\chi^{2}$ & Parameter & $\operatorname{Pr}>\chi^{2}$ \\
\hline Intercept & 9.176 & 0.158 & -7.870 & 0.009 & 4.343 & 0.481 \\
Eco_stage & -2.351 & 0.046 & & & -2.606 & 0.018 \\
GDP_PPP & & & 0.000 & 0.027 & 0.000 & 0.003 \\
Institutions & -0.044 & 0.194 & -0.074 & $\mathbf{0 . 0 2 6}$ & -0.062 & $\mathbf{0 . 0 5 6}$ \\
Press_freedom & -0.037 & 0.046 & -0.044 & $\mathbf{0 . 0 1 6}$ & -0.031 & 0.068 \\
ELF & 9.636 & 0.000 & $\mathbf{5 . 4 2 9}$ & $\mathbf{0 . 0 5 0}$ & $\mathbf{7 . 4 6 9}$ & $\mathbf{0 . 0 0 3}$ \\
HDI & -0.016 & 0.640 & $-\mathbf{0 . 0 8 2}$ & $\mathbf{0 . 0 0 2}$ & -0.044 & 0.183 \\
$\boldsymbol{R}$-squared & 0.3309 & & 0.3393 & & 0.462 & \\
$\boldsymbol{N}$ & 132 & & 155 & & 132 &
\end{tabular}

(c) Dependent variable: WB_bribery2

\begin{tabular}{lcccccc}
\hline Variable & Parameter & $\operatorname{Pr}>\chi^{2}$ & Parameter & $\operatorname{Pr}>\chi^{2}$ & Parameter & $\operatorname{Pr}>\chi^{2}$ \\
\hline Intercept & -15.880 & 0.245 & -7.931 & 0.151 & -25.288 & 0.061 \\
Eco_stage & 4.339 & 0.080 & & & 3.211 & 0.183 \\
GDP_PPP & & & 0.000 & 0.000 & 0.000 & 0.001 \\
Institutions & -0.352 & $<0.0001$ & -0.307 & $<0.0001$ & -0.393 & $<0.0001$ \\
Press_freedom & -0.002 & 0.955 & 0.018 & 0.582 & 0.007 & 0.851 \\
ELF & -0.891 & 0.871 & -3.906 & 0.446 & -5.262 & 0.338 \\
HDI & -0.079 & 0.271 & -0.113 & 0.023 & -0.139 & 0.055 \\
$\boldsymbol{R}$-squared & 0.3585 & & 0.3875 & & 0.4019 & \\
$\boldsymbol{N}$ & 132 & & 155 & & 132 &
\end{tabular}

This table reports the robustness tests of the relationship between economic development, proxied by $E c c_{-}$stage and GDP_PPP, and level of corruption across countries. The results indicate that, in the presence of controls for governance (proxied by Institutions and Press_freedom), culture, and social development, Eco_stage, but not $G D P \_P P P$, is significant in explaining the variation in TI_CPI and WB_bribery1 but not WB_bribery2. P-values are reported for two-tailed tests based on robust errors. See Appendix for the definition of the variables. 
Table 9. Corruption and economic development - Africa - robustness tests. Corruption $_{i}=\alpha+\beta_{1}$ Eco_stage $_{i}+\beta_{2} G D P \_P P P_{i}+\beta_{3}$ Institutions $_{i}$

$$
+\beta_{4} \text { Press_freedom }_{i}+\beta_{5} E L F_{i}+\beta_{6} H D I_{i}+\varepsilon_{i}
$$

(a) Dependent variable: TI_CPI

\begin{tabular}{lcccccc}
\hline Variable & Parameter & $\operatorname{Pr}>\chi^{2}$ & Parameter & $\operatorname{Pr}>\chi^{2}$ & Parameter & $\operatorname{Pr}>\chi^{2}$ \\
\hline Intercept & -3.093 & 0.960 & 20.977 & 0.696 & 15.535 & 0.842 \\
Eco_stage & -3.949 & 0.717 & & & -2.763 & 0.807 \\
GDP_PPP & & & -0.001 & 0.467 & -0.001 & 0.681 \\
Institutions & -0.469 & $\mathbf{0 . 0 2 7}$ & -0.746 & $<0.0001$ & -0.512 & $\mathbf{0 . 0 2 2}$ \\
Press_freedom & -0.237 & 0.090 & -0.234 & 0.032 & -0.215 & 0.132 \\
ELF & -2.309 & 0.891 & -9.453 & 0.490 & -2.168 & 0.899 \\
HDI & -0.323 & 0.298 & -0.002 & 0.996 & -0.198 & 0.648 \\
$\boldsymbol{R}$-squared & 0.5585 & & 0.5798 & & 0.5635 & \\
$\boldsymbol{N}$ & 33 & & 45 & & 33 & \\
\hline
\end{tabular}

(b) Dependent variable: WB_bribery1

\begin{tabular}{lcccccc}
\hline Variable & Parameter & $\operatorname{Pr}>\chi^{2}$ & Parameter & $\operatorname{Pr}>\chi^{2}$ & Parameter & $\operatorname{Pr}>\chi^{2}$ \\
\hline Intercept & 11.786 & 0.427 & 9.743 & 0.692 & 2.171 & 0.911 \\
Eco_stage & $-\mathbf{4 . 7 2 4}$ & $\mathbf{0 . 0 7 2}$ & & & -4.637 & $\mathbf{0 . 0 9 8}$ \\
GDP_PPP & & & 0.000 & 0.608 & 0.000 & 0.573 \\
Institutions & $-\mathbf{0 . 1 5 8}$ & $\mathbf{0 . 0 0 2}$ & $-\mathbf{0 . 1 9 8}$ & $\mathbf{0 . 0 1 3}$ & $-\mathbf{0 . 1 5 2}$ & $\mathbf{0 . 0 0 6}$ \\
Press_freedom & 0.020 & 0.560 & -0.004 & 0.944 & 0.013 & 0.710 \\
ELF & 12.140 & 0.003 & 4.338 & 0.490 & 11.722 & 0.006 \\
HDI & 0.021 & 0.775 & 0.072 & 0.637 & -0.034 & 0.754 \\
$\boldsymbol{R}$-squared & 0.4934 & & 0.2134 & & 0.497 & \\
$\boldsymbol{N}$ & 33 & & 45 & & 33 & \\
\hline
\end{tabular}

(c) Dependent variable: WB_bribery2

\begin{tabular}{lcccccc}
\hline Variable & Parameter & $\operatorname{Pr}>\chi^{2}$ & Parameter & $\operatorname{Pr}>\chi^{2}$ & Parameter & $\operatorname{Pr}>\chi^{2}$ \\
\hline Intercept & 0.150 & 0.996 & 34.865 & 0.280 & 10.965 & 0.788 \\
Eco_stage & 6.224 & 0.277 & & & 6.666 & 0.258 \\
GDP_PPP & & & 0.000 & 0.993 & 0.000 & 0.675 \\
Institutions & -0.321 & 0.004 & -0.290 & 0.006 & -0.332 & 0.005 \\
Press_freedom & -0.037 & 0.616 & -0.009 & 0.894 & -0.031 & 0.681 \\
ELF & 4.597 & 0.604 & 4.195 & 0.611 & 4.209 & 0.638 \\
HDI & 0.064 & 0.697 & 0.187 & 0.349 & 0.129 & 0.570 \\
$\boldsymbol{R}$-squared & 0.3226 & & 0.215 & & 0.3282 & \\
$\boldsymbol{N}$ & 33 & & 45 & & 33 &
\end{tabular}

This table reports the robustness tests of the relationship between economic development, proxied by Eco_stage and GDP_PPP, and level of corruption for African countries. The results indicate that, in the presence of controls for governance (proxied by Institutions and Press_freedom), culture, and social development, Eco_stage is significant in explaining the variation in WB_briberyl but not TI_CPI or WB_bribery2. GDP_PPP is not significant in any specification. P-values are reported for two-tailed tests based on robust errors. See Appendix for the definition of the variables. 


\section{Discussion and Conclusion}

This paper assesses to what extent corruption is related to a country's stage of economic development, and how this relationship is sensitive to a country's governance systems, culture, and social development. We argue that corruption coevolves with a country's political processes (or effectiveness of governance), culture, social norms, and similar factors. Thus, it becomes imperative to approach corruption from a multidimensional perspective.

We have taken the most parsimonious viewpoint in operationalizing these various concepts quantitatively. The conceptual difficulties are matched in severity by the difficulties of data and therefore the statistical methods employed. The concepts are nebulous, the indicators are many but imprecise and data are sparse. Therefore, we use regression analysis to extract as much of relationship between explanatory variables and the variable of corruption as possible.

Given the results of the full sample and the African subsample, we surmise that as a country moves along the path of economic development, corruption tends to recede. However, the causality question becomes more answerable in the sense of "chicken first or egg first". Governance related factors such as institutions and freedom of the press appear to be salient across samples and robust to different measures of corruption. As the appendix shows, the institution variable covers a country's political, regulatory, and business environment; freedom of the press represents the legal, political, and economic environments for the press.

Our findings have policy implications for the worldwide battle against corruption and especially the anti-corruption efforts of African nations. Effective governance thrives in developed economies, where the rule of law and transparency permeate the country's economy and political systems, resulting in a functioning state with commitment to lawful use of public goods and services. Corruption is not a fixed feature of underdeveloped economies; but to combat poverty and corruption, a nation must address its governance issues by establishing institutions of law and order and promoting transparency in executive, legislative, and judiciary decisions. Freedom of information and the press are important components for the creation of a transparent, equitable, and inclusive economic, political, and social environment. It is of paramount importance for African countries to invite the participation of their civil societies in their political, social, and economic transformations. The implementation of governance measures must be well aligned with the country's local realities in terms of social development and heterogeneous cultural traditions.

\section{Conflicts of Interest}

The authors declare no conflicts of interest regarding the publication of this paper.

\section{References}

[1] Treisman, D. (2007) What Have We Learned about the Causes of Corruption from 
Ten Years of Cross-National Empirical Research? Annual Review of Political Science, 10, 211-244. https://doi.org/10.1146/annurev.polisci.10.081205.095418

[2] Egbue, N. (2006) Africa: Cultural Dimensions of Corruption and Possibilities for Change. Journal of Sociology Science, 12, 83-91.

https://doi.org/10.1080/09718923.2006.11978361

[3] Atuobi, S. (2007) Corruption and State Instability in West Africa: An Examination of Policy Options. KAIPTC Occasional Paper.

[4] Gyimah-Brempong, K. (2002) Corruption, Economic Growth and Income Inequality in Africa. Economics of Governance, 3, 183-209.

https://doi.org/10.1007/s101010200045

[5] Ebegbulem, J. (2012) Corruption and Leadership Crisis in Africa: Nigeria in Focus. International Journal of Business and Social Science, 3, 221-227.

[6] Mishra, P. and Maiko, S. (2017) Combating Corruption with Care: Developing Ethical Leaders in Africa. Africa Journal of Management, 3, 128-143.

https://doi.org/10.1080/23322373.2016.1275942

[7] Sobjak, A. (2018) Corruption Risks in Infrastructure Investments in Sub-Saharan Africa. OECD Global Anti-Corruption \& Integrity Forum, Paris, 27-28 March 2018. https://tinyurl.com/y6gy7jg4

[8] Rose-Ackerman, S. (1999) Corruption and Government: Causes, Consequences, and Reform. Cambridge University Press, New York. https://doi.org/10.1017/CBO9781139175098

[9] Wambua, P. (2015) Police Corruption in Africa Undermines Trust, But Support for Law Enforcement Remains Strong. Afronarometer Dispatch, No. 56. http://www.afrobarometer.org

[10] Badet, G., Damiba, L., Engueléguélé, S.B., Gaima, E., Iwuamadi, C.K., Ndiaye, S. and Williams, S. (2016) Effectiveness of Anti-Corruption Agencies in West Africa. Open Society Foundations, New York.

[11] Osifo, C. (2015) Evaluating Governance and Management in Africa. Proceedings of the University of VAASA, Public Management 5, University of Vaasa, Vaasa, Working Paper 8.

[12] Olaniyan, K. (2004) The African Union Convention on Preventing and Combating Corruption: A Critical Appraisal. African Human Rights Law Journal, 4, 74-92.

[13] Simplice, A. (2012) Fighting Corruption in Africa: Do Existing Corruption-Control Levels Matter? MPRA Archive, Munich.

[14] Mo, P. (2001) Corruption and Economic Growth. Journal of Comparative Economics, 29, 66-79. https://doi.org/10.1006/jcec.2000.1703

[15] Mulinge, M. and Lesetedi, G. (2002) Corruption in Sub-Saharan Africa: Towards a More Holistic Approach. African Journal of Political Science, 7, 51-77. https://doi.org/10.4314/ajps.v7i1.27324

[16] Mzansi, B. (2016) Corruption Watch Annual Report 2016. http://www.corruptionwatch.org.za

[17] Bamidele, O. (2013) Corruption, Conflict and Sustainable Development in African States. The African Symposium: An Online Journal of the African Educational Research Network, 13, 42-54.

[18] Nanziri, T. (2014) Beyond Bribery: Rethinking the Form of Corruption in Sub-Saharan Africa's Extractive Industries. Master of Laws, Faculty of Law, University of Toronto, Toronto.

[19] Lumumba, P.L.O. (2014) Corruption: The Bane of Africa. Corruption in Africa: A 
Threat to Justice and Sustainable Peace. 18.

[20] UN (2003) Country Corruption Assessment Report: South Africa. UN Office on Drugs and Crime, Regional Office for Southern Africa, Pretoria, South Africa.

[21] Bojang, M. (2017) Critical Issues Affecting Africa's Development: E-Government, Democracy and Democratic Principles, and Governance as an Alternative for Socio-Economic Development in Africa. International Journal of Youth Economy, 1, 41-55. https://doi.org/10.18576/ijye/010104

[22] Amadi, L. and Ekekwe, E. (2014) Corruption and Development Administration in Africa: Institutional Approach. African Journal of Political Science and International Relations, 8, 163-174. https://doi.org/10.5897/AJPSIR2013.0634

[23] Ganahl, J. (2013) Corruption, Good Governance, and the African State. Potsdam Economic Studies 2. Potsdam University Press, Potsdam.

[24] Hausmann, R., et al. (2013) The Atlas of Economic Complexity: Mapping Paths to Prosperity. Harvard University Center for International Development, MIT Press.

[25] Nathaniel, A. (2014) Corruption and Underdevelopment in Africa: A Discourse Approach. International Journal of Economics, Commerce and Management, 2, $1-14$.

[26] Pride Nkwinja, N. (2015) The Economic Impact of Corruption in Africa and The Way Forward-Case Study Cameroon. Thesis, Centria University of Applied Sciences, Kokkola.

[27] OECD (1997) OECD Convention on Combating Bribery of Foreign Public Officials in International Business Transactions. OECD, Paris. http://www.oecd.org/corruption/oecdantibriberyconvention.htm

[28] AGOA (2000) African Growth and Opportunity Act. https://www.trade.gov/agoa

[29] OECD (2014) OECD Foreign Bribery Report: An Analysis of the Crime of Bribery of Foreign Public Officials. OECD, Paris.

[30] Buehn, A. and Schneider, F. (2009) Corruption and the Shadow Economy: A Structural Equation Model Approach. Working Paper, Institute for the Study of Labor (IZA), University of Bonn, Bonn.

[31] Manzin, M., Bavec, C. and Čurin, S. (2012) Resiliency to Corruption-Structural Model of Causalities and Consequences. Revijaza Kriminalistiko in Kriminologijo, 63, 281-290.

[32] Serra, D. (2006) Empirical Determinants of Corruption: A Sensitivity Analysis. Public Choice, 126, 225-256. https://doi.org/10.1007/s11127-006-0286-4

[33] Desmet, K., Ortuño-Ortín, I. and Wacziarg, R. (2012) The Political Economy of Ethnolinguistic Cleavages. Journal of Development Economics, 97, 322-338. https://doi.org/10.1016/j.jdeveco.2011.02.003

[34] Desmet, K., Ortuño-Ortín, I. and Wacziarg, R. (2009) The Political Economy of Ethnolinguistic Cleavages. NBER Working Paper No. 15360. https://doi.org/10.3386/w15360

[35] Alesina, A., Devleeschauwer, A., Easterly, W., Kurlat, S. and Wacziarg, R. (2003) Fractionalization. Journal of Economic Growth, 8, 155-194. https://doi.org/10.1023/A:1024471506938

[36] World Bank (2010) Literature Survey on State Capture, Grand Corruption \& Political Corruption 1995-2010. Public Sector Governance, Poverty Reduction \& Economic Management, Washington DC. http://siteresources.worldbank.org/PUBLICSECTORANDGOVERNANCE/Resourc 
es/285741-1315337528748/LitSurveyAnticorruptionStateCapture.pdf

[37] Huber, P.J. (1967) The Behavior of Maximum Likelihood Estimates under Nonstandard Conditions. In: Proceedings of the 5 th Berkeley Symposium in Mathematical Statistics, Volume 1, University of California Press, Berkeley, 221-233. 


\section{Appendix}

Variable Definition.

TI_CPI The Corruption Perception Index of 2016 published by Transparency International. It ranks countries by their "perceived levels of public sector corruption, as determined by expert assessments and opinion surveys." The country with the lowest perceived level of corruption ranks 1st. At the score of 90 Denmark ranks 1 with lowest corruption whereas at the score of 10 Somalia ranks 176 with the highest corruption.

WB_briberyl Bribery incidence based on World Bank Enterprise Survey as of 2017. It measures the percent of firms experiencing at least one bribe payment request across 6 public transactions dealing with utilities access, permits, licenses, and taxes.

WB_bribery2 Percent of firms identifying corruption as a major constraint, based on World Bank Enterprise Survey as of 2017.

Econ_stage Stage of development based on the World Economic Forums' Global Competitiveness Report 2017-2018, coded 1, 3, and 5 for factor-driven, efficiency-driven, and innovation-driven economies, respectively; coded 2 for economies in transition from factor-driven to efficiency-driven and 4 for economies in transition from efficiency-driven to innovation-driven. The data used by the report to determine stage of development cover the years 2012 through 2016.

GDP_PPP 2016 GDP per capita based on purchasing power parity (PPP) in 2011 international dollars published by the World Bank.

Institutions $\quad$ Ranks of institutions as one of the five input pillars of the Global Innovation Index of 2015. The institutions pillar covers a country's political, regulatory, and business environment. The country with the strongest institutions ranks 1 st. We multiply the original rank by -1 so that a greater value denotes stronger institutions. The Global Innovation Index is published by Cornell University, INSEAD, and World Intellectual Property Organization.

Press_freedom Press freedom index of 2015 compiled and published by Reporters Without Borders. The country with the highest press freedom ranks 1st. We multiply the original rank by -1 so that a greater value denotes greater press freedom.

$E L F$

Ethno-linguistic fractionalization score that measures the probability that two randomly selected people from a given country will not belong to the same ethnolinguistic group. The score is between 0 (zero fractionalization) and 1 (highest fractionalization). It is based on the work of Desmet, Ortuño-Ortín and Wacziarg (2012, 2009) and Alesina, Devleeschauwer, Easterly, Kurlat, and Wacziarg (2003). The data are available under the link http://www.anderson.ucla.edu/faculty_pages/romain.wacziarg/downloads/2012_DOW_data.xls. The scores are calculated at 15 different levels of aggregation. We have used the aggregation level 8.

Human Development Index (HDI) based on the United Nations Human Development Reports of 2016. It is a composite index measuring average achievement in three basic dimensions of human development-a long and healthy life, knowledge, and a decent standard of living. The country with the highest human development ranks 1 st. We multiply the original rank by -1 so that a greater value denotes greater human development. 